\title{
MULHERES DE ATITUDE, MULHERES QUE OCUPAM: RELATO E PROBLEMATIZAÇÕES DE UMA EXPERIÊNCIA ARTÍSTICA
}

\author{
Juliana de Lima Veloso ${ }^{\mathrm{i}}$
}

\begin{abstract}
Resumo
O presente relato se baseia em expor um pouco do processo do projeto Mulheres de atitude, mulheres que ocupam, que foi realizado entre os meses de Outubro de 2016 a Fevereiro de 2017 e que por finalização teve como resultado uma ocupação artística nas dependência da Universidade Federal do ABC. Escrito como um Escrito de Artista o relato desta experiência vem agregar juntamente com algumas questões pertinentes ao campo das artes visuais e educação, um relato de caráter poético artístico. Partindo da ideia de "tornar-se" uma experiência artística entre artista e modelos o projeto vigente trouxe oportunidade à comunidade de mulheres de se aproximar das artes. O mesmo teve como objetivo o intuito de desmistificar os conceitos de modelo vivo, modelo como musa e corpo nu. Produzindo reflexões dentro do campo das artes visuais, sobre o corpo da mulher, a idealização da beleza e dos padrões estéticos vigentes em nossa sociedade. A experiência intencionou promover a compreensão de que todo e qualquer tipo de corpo pode e deve ser visto, posando ou não, o corpo da mulher deve ser valorizado. Já dentro do campo da educação a experiência do projeto veio agregar indagações acerca dos poderes das imagens e as possíveis pedagogias visuais que as mesmas carregam. Como artista visual e professora de artes meus pensamentos e minhas práticas aqui presentes neste relato não poderiam deixar de estar amarrados às questões da arte e da educação. É na linha foucaultiana que sigo escrevendo e pensando meus fazeres.
\end{abstract}

Palavras-chave: ocupação artística, experiência, desenho, arte, educação.

\section{WOMEN OF ATTITUDE, WOMEN WHO OCCUPY: REPORT AND PROBLEMATIZATIONS OF AN ARTISTIC EXPERIENCE}

\begin{abstract}
The present report is based on exposing some of the process of the "Women of attitude, women who occupy" project, that took place between October 2016 to February 2017 and that by finalization resulted in an artistic occupation in the Federal University of ABC grounds. Written as an Artist's Written, the report of this experience brings together, along with some pertinent questions in the field of visual arts and education, an artistic poetic report. Starting from the idea of "becoming" an artistic experience between artist and models, the current project provided an opportunity for the women's community to approach the arts. The objective was to demystify the concepts of the living model, model as muse and naked body. Producing reflections within the field of the visual arts, on the body of the woman, on the idealization of beauty and aesthetic standards in our society. The experience intended to promote the understanding that any and all types of body can and should be seen, whether or not exposed, the woman's body should be valued. Within the field of education, the experience of the project has raised questions about the power of the images and the possible visual pedagogies they carry. As a visual artist and an art teacher, my thoughts and practices present in this report could not fail to be tied to the issues of arts and education. It is on the Foucaultian line that I continue to write and think about my actions.
\end{abstract}

Key words: artistic occupation, experience, drawing, art, education 


\section{O convite e a proposta}

A partir de um convite feito pela Universidade Federal do ABC, em Setembro de 2016, pelo Ofício no 119/2016/ProEC, fui solicitada a pensar e realizar uma ocupação artística nos espaços de convivência, que como consta no ofício "estão sendo repensados de modo a promover os valores estéticos, humanos e artísticos na comunidade interna e externa." ${ }^{\mathrm{ii}} \mathrm{O}$ espaço escolhido pela curadoria (realizada pela OMA Galeriaiii) para ocupar, foi um painel de 25 metros de comprimento por 2,05 metros de altura, situado na Biblioteca do Campus Santo André, São Paulo.

Ressalto para o leitor, antes de tudo, que sou artista visual e professora de artes no ensino público de Santa Catarina, sendo assim julgo que meus pensamentos e minhas práticas aqui presentes neste relato não poderiam deixar de estar amarrados às questões da arte e da educação.

Alicerçada nas problemáticas estéticas e na temática que minha poética visual transita que são as questões de gênero, a mulher e seu corpo, as questões estéticas e suas problemáticas no contemporâneo, promovi um projeto pessoal que foi inicialmente realizado a parte da ocupação, a qual o intitulei "Mulheres de atitude, mulheres que ocupam". No final desse projeto a ocupação artística levou o mesmo título e teve como duração quatro meses para sua exposição.

Desejando há tempos em minha produção aproximar-me mais ainda de meu objeto de pesquisa, a mulher, propus na internet uma chamada pública com a finalidade de convidar e incentivar mulheres diferentes de três estados brasileiros a posar para alguns desenhos de minha autoria. Os desenhos se dariam em sessões e encontros onde as modelos poderiam posar da forma que se sentissem mais confortáveis. Poderiam posar de roupa, seminuas ou nuas, individuais ou em grupos. A proposta era aberta e inclusiva.

Os desenhos realizados serviriam como matéria prima para a ocupação que se daria em Fevereiro de 2017. Assim durante os meses de Outubro de 2016 a Fevereiro de 2017 dediquei meu tempo a divulgar a chamada, agendar as sessões e desenhar essas mulheres.

O objetivo desse projeto foi "tornar-se" uma experiência viva entre artista e modelos, promovendo a aproximação da comunidade de mulheres às artes visuais. Através da ação de posar me propus desmistificar, entre as mulheres, os conceitos de modelo vivo, modelo como musa e corpo nu. Almejei produzir reflexões acerca da estética no campo das artes visuais, sobre o corpo da mulher, sobre a idealização da beleza e os padrões estéticos de nossa sociedade. A experiência devia promover a compreensão de que todo e qualquer tipo de corpo pode e deve ser visto, respeitado, posando ou não. 
A seguir o presente relato assim como em um Escrito de Artista ${ }^{i v}$ trará de forma mais subjetiva, o que me passou, o que aconteceu e que ainda me toca ${ }^{v}$ acerca dessa experiência, e quiçá em seu término, levantar alguns dados e questões importantes para o campo da arte e da educação.

\section{O processo}

Ao longo dos meses de Outubro de 2016 a Fevereiro de 2017, estive com 42 mulheres diferentes, entre 18 e 84 anos, em sessões e encontros para desenhá-las. Participaram mulheres de Criciúma e região (SC), Porto Alegre e região (RS) e $\mathrm{ABC}$ Paulista (SP). Ao término do projeto havia realizado 160 desenhos.

Os encontros em sua maioria foram marcados pela internet. Parentes, amigas, amigas de amigas, mãe de amigas, amigas dessa mãe e desconhecidas me procuraram para posar. Vieram via recados, mensagens e e-mails, para saber mais informações sobre o projeto, como aconteceriam as sessões e como deveriam posar. Algumas, mais tímidas, avisavam de antemão que não posariam nuas, outras sem nenhum problema desejavam posar e participar a todo peso do projeto.

Depois de marcar os encontros, que foram em diferentes lugares (em minha casa, casa de amigas e amigos, e um atelier de arte), as mulheres posaram no método clássico, que se sucedeu da seguinte forma: eu utilizei o cavalete, o lápis grafite e o papel sulfite A3; as modelos posaram em poses escolhidas por mim ou por elas, em pé, sentadas e deitadas.

Cada mulher posou onde e como se sentiu mais confortável, em uma sessão que durou cerca de 1h30min para cada mulher. Houve sessões mais longas, por exemplo, uma que durou $12 \mathrm{~h}$, na qual precisei desenhar oito mulheres em um dia inteiro.

Quando as recebia em casa, propunha um cafezinho para lhes contar um pouco do projeto e da ocupação. Eu as ouvia e conversávamos sobre os motivos que as levaram a posar, combinávamos o tempo e as posições, em seguida começávamos a sessão. Quando visitei outras casas, precisei “improvisar” um estúdio, montar cavalete, pedestal e algumas zonas de suporte. Nesses encontros na casa de amigas e amigos foram os momentos onde houve reunião de mulheres. Elas iam surgindo durante as sessões e assim nos encontrávamos em uma convenção de mulheres falantes e animadas. Em todos os encontros muitas conversas rolaram, histórias foram contadas e experiências compartilhadas. 
Os desenhos, dependendo do tempo disponível da modelo, se sucediam da seguinte forma:

$1^{\circ}$ posavam em pé, em posições mais cansativas, desde poses clássicas a poses inusitadas ${ }^{\mathrm{vi}}$; esses desenhos demoravam entre 10 à 20 minutos;

$2^{\circ}$ posavam sentadas, em posições clássicas a poses inusitadas; esses desenhos também demoravam entre 10 à 20 minutos;

$3^{\circ}$ posavam deitadas, em posições clássicas a poses inusitadas; esses desenhos demoravam entre 15 à 20 minutos;

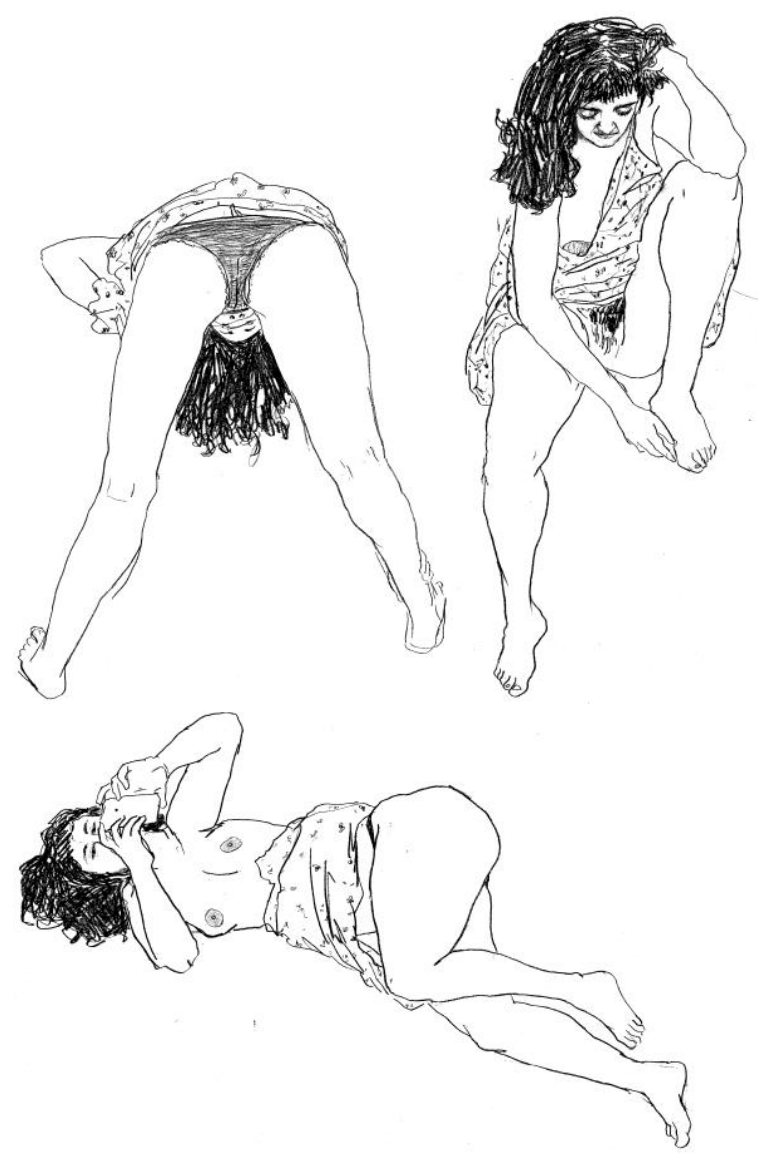

\author{
Fonte: Arquivo pessoal. Três \\ desenhos digitalizados para \\ ilustrar os três tipos de situação \\ em que as modelos posavam, em \\ pé, sentadas e deitadas. Estes \\ desenhos foram realizados para a \\ ocupação artística: Mulheres de \\ atitude, mulheres que ocupam. \\ Técnica: Desenho sobre papel \\ sulfite \\ Dimensões: $29,7 \times 42 \mathrm{~cm}$ (cada) \\ Ano de criação: 2016 e 2017
}

Através do que ouvi e que pude notar, essas posições para as modelos foram bastante cansativas, principalmente as de pé. Como em sua maioria, essas mulheres nunca posaram antes e sabendo aqui que para posar é necessário o esforço físico de ficar parada por alguns minutos, reparei ao ouvir de comentários que mesmo sendo algo extremamente cansativo, o fato de estarem "fazendo parte de um processo artístico", de estarem virando "obra de arte", as fascinava e as faziam lutar contras as suas dores musculares, câimbras e cansaço.

Também passei muitas horas em pé, sentindo dor apenas no braço direito. Quando sentava, precisava igual usar o mesmo braço para desenhar, era uma luta travada entre a dor de 
meu braço e o desejo de terminar o desenho. Às vezes fazia pausas para descanso, mas a vontade de terminar logo era grande, de ver o resultado e de mostrar à minha modelo como a vejo: como fonte de inspiração. De mostrar-lhes como, apesar de diferente de todas as outras, o seu corpo é lindo e deve ser amado e respeitado, seja posando para mim ou apenas visto pelos outros.

As sessões de desenho foram para mim uma espécie de estado de transe. Uma situação totalmente desafiadora para mente e corpo, onde o que acontecia em meu interior e exterior era a experiência em si. Visto que ao mesmo tempo em que percebia necessário concentrar meu olhar entre papel e modelo, meus ouvidos e outros sentidos estavam tão presentes e imersos na relação ao que acontecia entre eu e a modelo que me deixei viver cem por cento as histórias de vida contadas por cada uma. Foi a partir desse instante que notei que o que estava vivendo era o que objetivava desde o início, esse momento tornava-se uma experiência viva entre eu e modelos, onde as questões que propunha refletir estavam acontecendo durante o processo que estávamos vivendo.

Neste ponto é importante ressaltar que muitas das mulheres que desenhei, já estavam inseridas de alguma forma no campo das artes, sendo desde expectadoras e amantes da arte, até artistas, educadoras e pesquisadoras da área. As demais mulheres eram completamente alheias a essa esfera, algumas chegaram até mim pelo simples fato de perceber "que a vida só vale a pena pelas experiências que nos deixamos viver, e que se existe a possibilidade de fazer algo que nunca fiz, por que não fazer?" (conforme relato de uma modelo de 54 anos).

Ao longo desses meses de trabalho, pude notar três motivações principais para posar. Primeiro motivo: o simples fato de fazer parte de minha poética, porque já a conheciam. Essas mulheres são em sua maioria amigas e conhecidas. Segundo motivo: o desejo de virar "obra de arte", aproximar-se da arte, não do conceito de arte onde o artista é um homem, gênio, mito, e sim de uma obra de arte de uma amiga, da mulher artista, daquela que está "próxima de mim", "daquela que eu conheço" (como algumas comentaram). E o terceiro: o desejo de manifestar-se através de seu corpo, através de sua afirmação como mulher. Aqui percebo, por parte dessas modelos, uma vontade de resistir, pelo fato de desejarem através de sua pose, expor o seu discurso feminista, como as figuras a seguir. 

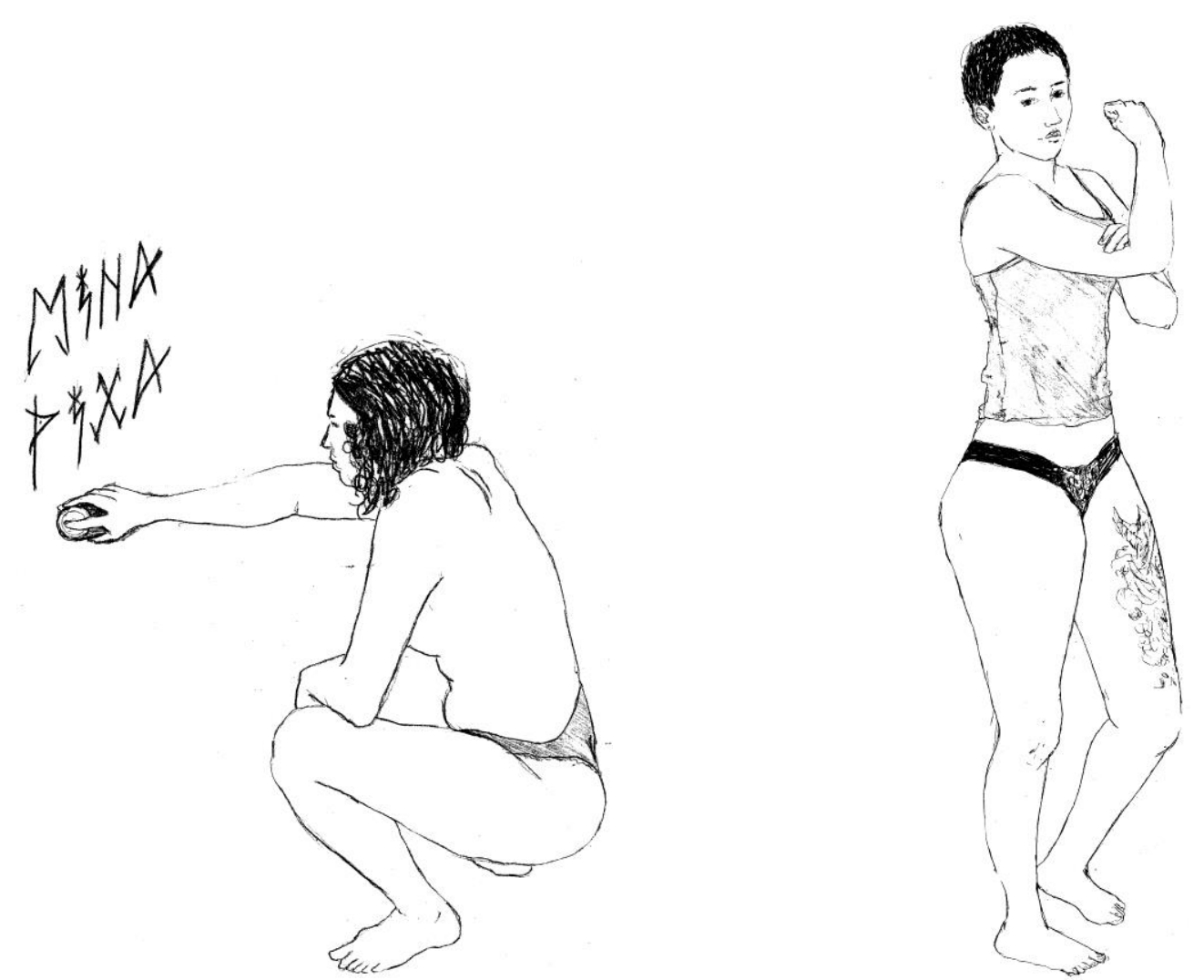

Fonte: Arquivo pessoal. Aqui dois desenhos digitalizados de duas mulheres que fizeram questão de posar nessas posições. Estes desenhos foram realizados para a ocupação artística: Mulheres de atitude, mulheres que ocupam.

Técnica: Desenho sobre papel sulfite.

Dimensões: $29,7 \times 42 \mathrm{~cm}$ (cada)

Ano de criação: 2016 e 2017

Logo, não poderia deixar de fazer relação aos movimentos de resistência que estavam acontecendo durante o ano de 2016 e que vinham se sucedendo desde os acontecimentos políticos de 2015. Escolas, universidades e instituições públicas ocupadas. Estudantes e comunidades unindo-se pelos mesmos motivos: a luta por direitos básicos à educação, saúde e outros. Nesse contexto o convite para a ocupação se encaixou como uma luva, onde, poder dar voz às mulheres e espaço para elas literalmente ocuparem, foi de imensa importância para mim e para elas. 

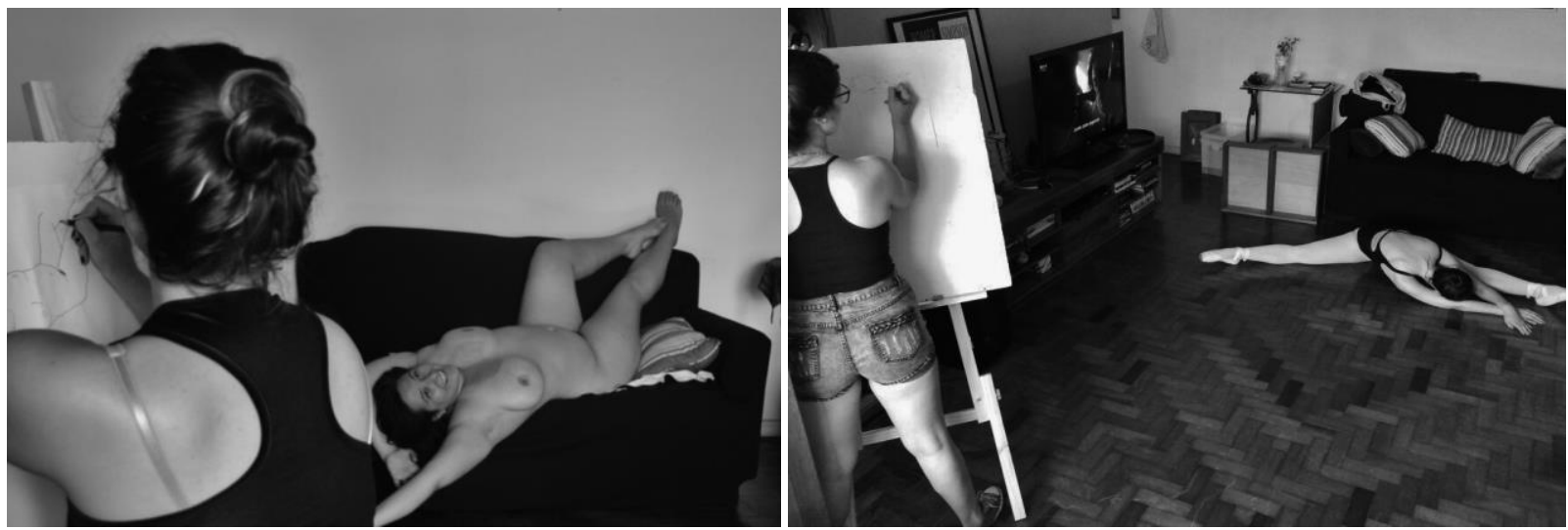

Fonte: Arquivo pessoal. Fotos digitais, realizadas durante encontros diferentes, do projeto "Mulheres de atitude, mulheres que ocupam” em 2016.

Compreender que durante o processo artístico as diferenças entre as mulheres só destacaram e ajudaram a trazer mais potência ao projeto, é de grande valia para mim. As relações que se estabeleceram entre mim e as modelos me fizeram acreditar em um certo empoderamento da mulher contemporânea e a questionar as visualidades de minha poética, sobre essas discorrerei ao final deste relato. A seguir prosseguirei com o relato da ocupação artística na UFABC e os retornos que tive durante um bate-papo com a comunidade de Santo André.

\section{A ocupação e algumas indagações}

Dos dias 13 a 17 de Fevereiro de 2017, fui à São Paulo para concluir o meu projeto e executar a ocupação artística na Universidade Federal do ABC. Lá permaneci na cidade de São Bernardo do Campo e Santo André.

Nos primeiros dias me propus a desenhar as mulheres da região, com as quais já havia me comunicado e marcado sessões para desenhá-las. Como não pude levar para a viagem o cavalete, os desenhos seguintes foram realizados em prancheta, lápis grafite e papel sulfite A4. Cinco mulheres posaram no estado de São Paulo.

Sendo a Universidade Federal do ABC uma universidade pública, fui solicitada no início da ocupação, a escolher entre utilizar os materiais que a própria universidade usufruía (como papéis, impressões, colas e materiais do almoxarifado), ou utilizar de materiais próprios trazendo-os, e/ou utilizando de verba própria para a execução. Escolhi utilizar os materiais da própria universidade, visto que a ideia de colar lambe-lambes ${ }^{\mathrm{vii}}$ no painel era a minha primeira 
sugestão e dialogava com a própria relação da técnica, que é acessível, juntamente com o caráter político que o lambe-lambe carrega.

Após todos os desenhos terem sido realizados, digitalizei-os em uma gráfica. As imagens foram manipuladas e recortadas, recebendo apenas um contraste mais forte, para que ficassem com mais aspecto de fotocópia, que é um dos meios de reprodução dos cartazes lambe-lambe.

Chegando à universidade todas as imagens já estavam prontas para a ocupação (exceto os desenhos que realizei lá, que foram digitalizados pela própria universidade). Para me ajudar durante a ocupação uma querida amiga viajou comigo. Trabalhamos exaustivamente durante dois dias inteiros para preencher o painel de 25 metros de comprimento por 2,05 metros de altura com folhas tamanho A0 para o fundo e 160 desenhos digitalizados que viriam por cima desse papel. Formando assim um enorme painel literalmente ocupado por mulheres.

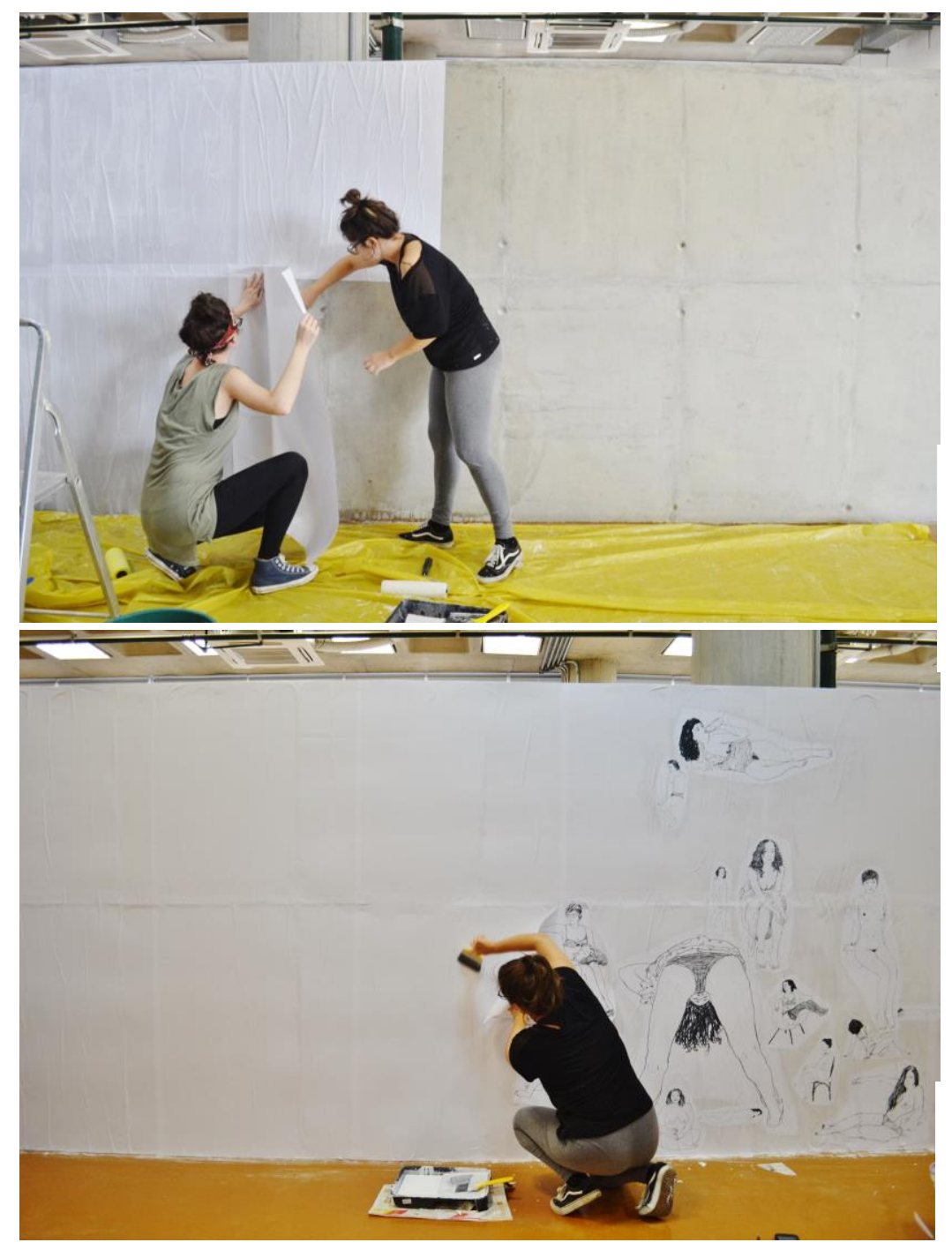

Fonte: Arquivo pessoal. Imagem digital tirada durante o primeiro dia de ocupação, colando as folhas A0 para fazer o fundo.

Fonte: Arquivo pessoal. Imagem digital tirada durante o segundo dia de ocupação, colando os lambe-lambes dos desenhos digitalizados. 


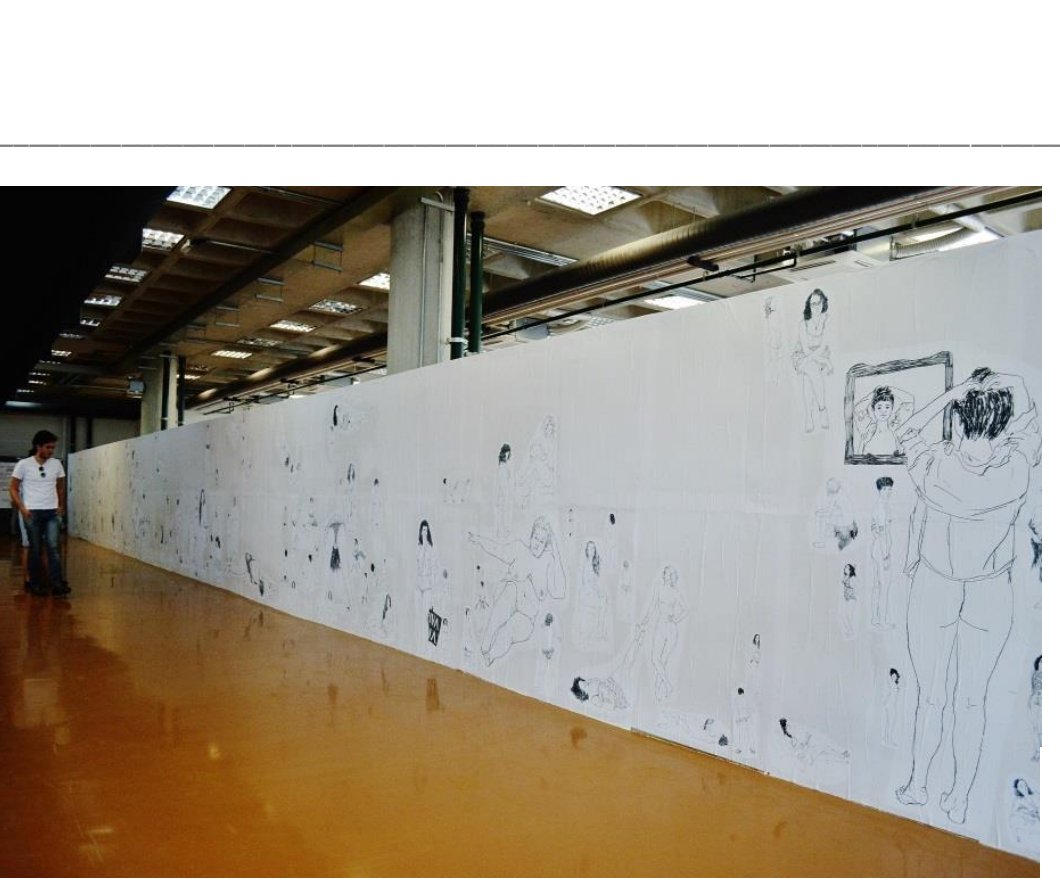

Fonte: Arquivo pessoal. Imagem digital tirada no terceiro dia. Abertura da ocupação.

No dia 17 de Fevereiro houve a abertura da ocupação com a fala do Vice-Reitor, do Setor de Cultura, do responsável pela Biblioteca e da curadoria, que foi realizada pela OMA Galeria. Após a abertura realizou-se um bate-papo com grupos convidados. Tivemos a presença dos representantes da Biblioteca, dos coletivos feminista e LGBT da Universidade Federal do ABC, a presença do Sindicato dos Trabalhadores das Universidades Federais do ABC liderado por duas mulheres, a Psicóloga da universidade, amigos e a comunidade em geral.

A conversa foi gratificante, se manteve acerca de questões que ambicionava no início do projeto, como por exemplo, o preconceito sofrido pelas mulheres dentro da universidade e fora dela. Também chegou ao debate o número significativamente inferior de mulheres acadêmicas, docentes e funcionárias que é de aproximadamente 1/3 (um terço) dentro da universidade. Esse dado nos mobilizou a pensar que mesmo os "corpos das mulheres ocupando o espaço público" (fala da psicóloga) onde e como estão esses corpos dentro de uma universidade que é também pública? Como uma ocupação feita por uma artista mulher a partir de 160 desenhos de corpos de 42 mulheres pode dialogar com essa ausência da representatividade da mulher na universidade? Será que ela só se dá nesse tipo de ambiente? Obviamente sabemos que não, ela está em toda a nossa sociedade.

Apesar das discussões terem sido fervorosas e de certa forma frustrante como mulher, ouvi lindas palavras de mulheres que participaram do projeto. Como o exemplo de uma modelo que representou a cidade de Santo André, ao relatar que durante o seu posar ela se sentiu "em uma reunião de irmãs" e outra fala de mulheres que gostariam de ter participado ao me perguntar "Você ainda vai desenhar mais mulheres? A gente quer participar!”.

A partir de todos esses retornos que tive, internos ou externos a minha pessoa, venho constatando que a experiência de posar, e a ação de desenhar outra mulher, tem andado de mãos 


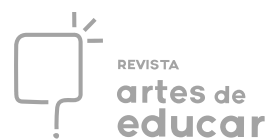

dadas com "um momento de autoafirmação", de empoderamento do corpo, de afirmação do espaço da mulher na sociedade e da "experiência de bem estar com meu próprio corpo"(fala de uma modelo).

Se na Europa dos séculos XVI ao XIX “às mulheres era vedado o acesso à prática de desenho do natural com modelo nu, que foi a base do ensino acadêmico e da representação." (CHADWICK, 1992), a mim nada disso foi vedado. Nasci no século posterior, onde as lutas desempenhadas pelas sufragistas ${ }^{\text {viii }}$ ajudaram a abrir o campo de batalha para mulheres na arte. E assim, me inspiro a entrar também nessa batalha de resistência, praticando e estudando o desenho nu, de e entre mulheres.

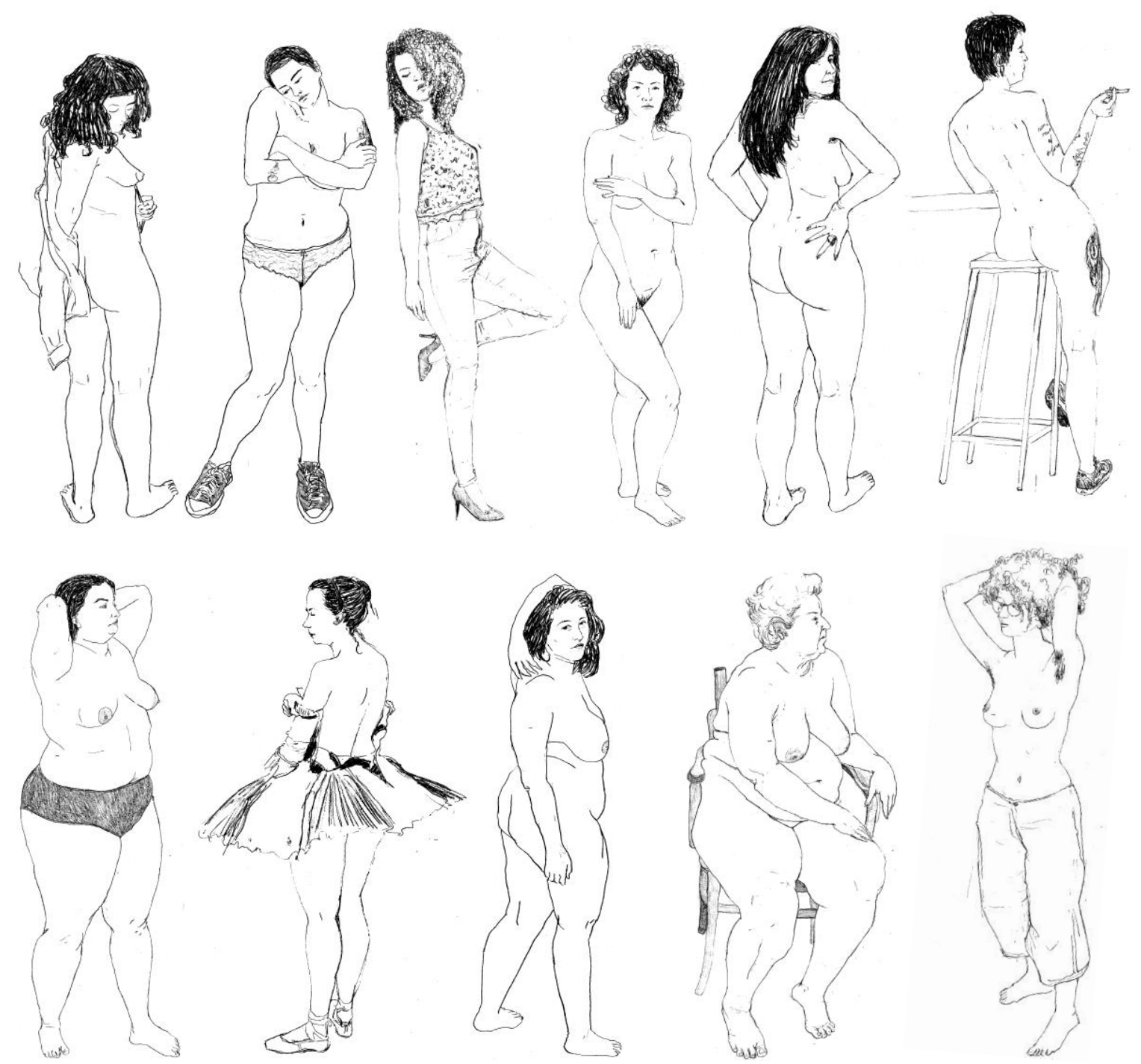

Fonte: Arquivo pessoal. Onze desenhos digitalizados de onze mulheres diferentes. Os desenhos originais medem $29,7 \times 42 \mathrm{~cm}$ (cada)

venho interrogando meus fazeres, artísticos e docentes. Pois como já dito anteriormente, sou 
professora de artes do ensino público, e dessa forma trabalho com imagens e conceitos que devem, ou deveriam, representar a arte, a sociedade e os contextos contemporâneos. E é assim, tocada por leituras, pesquisadoras e pesquisadores, que tenho seguido uma linha de pensamento voltada às questões de gênero na educação.

\section{Posar é poder, posar é empoderar-se}

Neste momento trago o pensamento foucaultiano para discutir um pouco a construção dos discursos e verdades acerca do corpo feminino. Seria possível através do entendimento de poder em Michel Foucault, "dar poder” ao corpo feminino? Lembro que neste momento o corpo de que falo é pensado não esteticamente, mas sim através de seus significados adquiridos ao longo da história.

Foucault que dedicou grande parte de sua obra a pesquisar e estudar o sujeito, os discursos e as relações de saber/poder vai tratar de rachar e investigar o que ele chamou de dispositivos, sendo um deles a sexualidade. Esse dispositivo no qual se insere o corpo humano, também irá assim como outros dispositivos, selecionar, regular e controlar modos de subjetivação na constituição dos sujeitos. Sendo assim, esses sujeitos subjetivados são resultado das constituições e práticas discursivas, afirmando-se nas relações de saber/poder. Sobre o termo dispositivo Judith Revel explica que o seu surgimento na obra de Foucault designa:

[...] inicialmente os operadores materiais do poder, isto é, técnicas, estratégias e formas de assujeitamento utilizadas pelo poder.[...] trata-se tanto de discursos quanto de práticas, de instituições quanto de táticas moventes: é assim que Foucault chega a falar, segundo o caso, de "dispositivos de poder", de "dispositivos de saber", de "dispositivos disciplinares", de "dispositivos de sexualidade" etc. (REVEL, p. 39, 2005)

Em seu livro Vigiar e Punir, Michel Foucault trabalha algumas questões importantes à sua pesquisa sobre o poder. Nesse desenvolve, por exemplo, a ideia de disciplina, onde teremos o revelar de corpos dóceis através de um poder disciplinar. Sobre a disciplina Foucault interpreta-a como "métodos que permitem o controle minucioso das operações do corpo, que realizam a sujeição constante de suas forças e lhes impõem uma relação de docilidadeutilidade" (2015) e continua:

[...] o corpo humano entra numa maquinaria de poder que o esquadrinha, o desarticula e o recompõe. Uma 'anatomia política', que é também igualmente uma 'mecânica do poder', está nascendo; ela define como se pode ter domínio sobre o corpo dos outros, não simplesmente para que façam o que se quer, mas para que operem como se quer [...] A disciplina fabrica assim corpos submissos e exercitados, corpos 'dóceis'. (FOUCAULT, p.127, 2015) 
Mesmo Foucault tendo estudado os corpos dentro de instituições que tentam disciplinar, vigiar e punir, como as prisões, hospitais e escolas, os discursos que se geraram, perpetuaram e instalaram verdades acerca dos corpos, perpetuaram também verdades e discursos nos corpos das mulheres. Ao pensarmos na construção histórica e social de uma padronização de corpo e representação da mulher:

Na história das mulheres a dimensão da linguagem, dos discursos, é uma ferramenta de análise importante, não como meio de representação da realidade, mas como representação. A linguagem não é só vocabulário, mas discurso que numa relação de saber e poder, determina verdades e nos subjetiva. (COLLING, p.181, 2014)

É nessa perspectiva foucaultiana que minha pesquisa poética com as mulheres no projeto tem trazido à tona algumas problematizações acerca desse corpo feminino que em sociedade está sempre sofrendo algum tipo de normatização. Logo as constituições de sentidos ao longo da história produziram discursos, saberes e poderes, "verdades" e mitos sobre a sexualidade e o corpo da mulher.

Mulheres nuas em diferentes corpos nunca foram tão explicitas em seus discursos. A vontade de posar e o ato de posar, representam aqui, em minha opinião o empoderamento do corpo e voz da mulher, visto que ao longo da história a mulher foi estudada e contada de um ponto de vista masculino e eurocêntrico. Verdades, regras e padrões desfigurados se criaram para falar deste corpo que não os pertencia. Dar poder através de uma experiência sensível e artística pode parecer sem sentido para alguns, mas não para aquelas que ganharam espaço, voz e um novo significado para seu corpo. Sobre o termo acima em inglês anglo-saxão "Empowerment":

[...] refere-se ao processo pelo qual através da educação, grupos sociais subordinados adquirem meios de fortalecer seu poder para lutar contra estruturas de opressão e dominação. Uma tradução possível é "fortalecimento do poder". (SILVA apud LOPONTE, 2000 p.49)

É com essa ideia de opressão e dominação que penso que não só o corpo físico da mulher se submeteu e subjugou aos dizeres e ordenares de um discurso masculino, como o discurso da mulher se sujeitou a perpetuar um discurso oficial que não era o seu, mas o que se estabelecia como padrão. Entender o seu próprio corpo de mulher não partia de uma visão subjetiva, mas sim de uma posição masculina. Simone de Beauvoir inaugura o segundo volume de sua obra $O$ Segundo Sexo (1967) com a frase "Ninguém nasce mulher: torna-se mulher" que veio não só estremecer, mas rachar conceitos biológicos, psíquicos, econômicos entre outros e que até hoje deixa sua marca no discurso feminista. 
É na falta histórica de um discurso próprio sobre seu corpo que o significado da palavra empoderamento encaixa-se no "ganho de poder", na conquista de voz e outros significados desse corpo feminino através do ato e vontade de posar para os desenhos.

\title{
$O$ contexto artístico e as ideias feministas
}

A/O artista visual contemporânea/o que traz para seu trabalho as discussões de gênero, identidade, feminismo, intolerância e preconceito de alguma forma estão inseridas/os num mesmo pensar: a diferença. Dentro do espectro do pensamento feminista há o que chamamos hoje de feminismo da terceira onda:

\begin{abstract}
A terceira onda abrange as tentativas de desconstrução da categoria "mulher" como um sujeito coletivo unificado que partilha as mesmas opressões, os mesmos problemas e a mesma história. Trata-se de reivindicar a diferença dentro da diferença. As mulheres não são iguais os homens, na esteira das ideias do feminismo de segunda onda, mas elas tampouco são todas iguais entre si, pois sofrem as consequências da diferença de outros elementos, tais como raça, classe, localidade ou religião. (SIQUEIRA, p.337, 2015)
\end{abstract}

Paula Alzugaray (2016) em seu artigo Feminismo em campo expandido para a revista Select discutirá o feminismo através dos diferentes discursos de artistas que tratam das rejeições e intolerâncias contra as singularidades e também da desconstrução da noção tradicional de gênero. Paula nos mostra que entre os artistas há diferentes pensamentos que não se fixam " $a$ um pensamento feminista estruturado apenas sobre as questões de sexo e de gênero", mas sim "feminismos expandidos ligados a causas políticas que atravessam gêneros, disciplinas e campos do pensamento.", como o exemplo do artista Laercio Redondo que discute as singularidades humanas e a reconstrução de memórias apagadas como a personagem Lota de Macedo Soares, arquiteta e urbanista. Ou ainda na obra de Thiago Martins de Mello:

Na pintura O Triângulo Impossível da Judith Negra e a Sedução do Útero da Razão (2012), a violência contra o índio é a violência contra o corpo feminino, que é a violência contra o negro, que é a violência contra a diversidade, que é a violência contra a liberdade de afetos. (ALZUGARAY, p.48, 2016)

Paula me faz pensar que essa discussão não diz respeito apenas à causa das mulheres ou ao pensamento feminista, mas a todos e todas que não se reconhecem no discurso oficial, que são a diversidade, a diferença. Concordo com a crítica de arte Lisette Lagnado (2016) quando em outra matéria da mesma revista dirá que "o feminismo é um modo de estar no mundo" e que "Não é a quantidade que fortalece o argumento do feminismo, mas as formas discursivas que emprega.". Nesse contexto das artes visuais, percebo que as mulheres que participaram do 
projeto se reconheceram de alguma forma nessa ocupação, onde o discurso de minha poética passa a ser o discurso de cada mulher e vice-versa.

Assim percebo e afirmo que meu discurso, relato, projeto poético e pesquisa tencionamse dentro dessa terceira onda. Onde a discussão sobre a constituição histórica dos discursos sobre corpo da mulher se expandem e transcendem para outras mais questões, como a problemática da estética, corpo enquanto imagem, padrões de beleza baseados em cânones, etc.

\section{A beleza e a permanência de um padrão}

Quem nunca ouviu falar de um "padrão de beleza" ou da "ditadura da beleza"? Pois é, termos como estética e beleza fazem parte de uma área de pesquisa muito antiga, filosoficamente e teoricamente falando. Há que se discutir e problematizar muito esses termos dentro da educação e artes visuais.

A construção de padrões de beleza, em diferentes momentos históricos, assim como em nossa contemporaneidade, prescreve e dita algumas normas diretas ou indiretamente sobre a vida das mulheres. Sendo mulher não consigo passar despercebida por um outdoor gigantesco que vende lingerie e ver uma mulher branca, magra, alta de rosto com traços finos. Não tem como não lembrar que as "mocinhas" escolhidas para filmes hollywoodianos ou para as novelas das principais emissoras de televisão seguem algum "padrão" de corpo, rosto, cabelos, enfim, padrões estéticos que conhecemos como beleza.

Na história, beleza ou o belo sempre foi associado a algo agradável, que nos dá prazer de olhar, que tem simetria e harmonia. Para os gregos pré-socráticos a beleza estava conectada à matemática. A escola pitagórica percebia que quanto mais os objetos estivessem dentro das proporções áureas mais atraentes eles eram. Sobre a razão áurea o autor e professor de matemática Eudes Antônio da Costa conta que os pitagóricos estudando um pentagrama descobriram:

[...] um número que desempenha um importante papel na geometria, na estética, nas artes, na arquitetura e na biologia. Este número é chamado de número áureo (número de ouro) ou razão (secção) áurea. A razão áurea, além de um conceito matemático, é uma expressão de harmonia e beleza. Os antigos gregos avaliavam essa harmonia nos seres vivos e não-vivos, buscando em suas dimensões uma proporção que se aproximasse da razão áurea. (COSTA, p.192, 2008) 


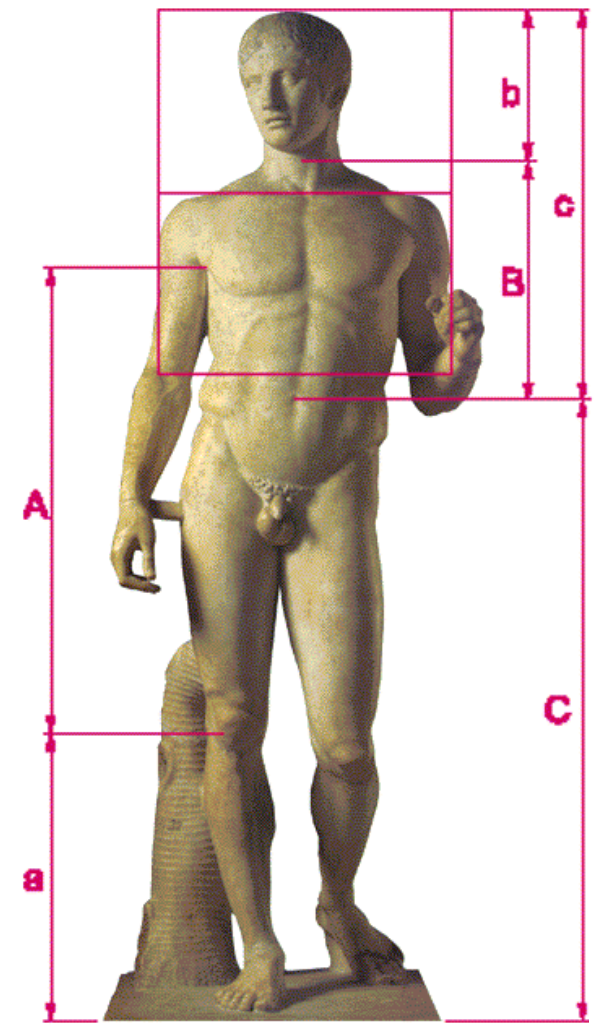

Fonte: Arquivo pessoal. Imagem que ilustra uma das possibilidades de medir o corpo humano através da proporção áurea.

Na Grécia, a maioria dos escultores utilizava ou da proporção áurea ou de algum cânone para criar suas peças. Ao longo dos anos essas esculturas passaram a ser minuciosamente estudas, repetidas e idolatradas como um padrão, fórmula a se seguir e reproduzir na escultura e pintura. Foi o que vimos no Renascimento.

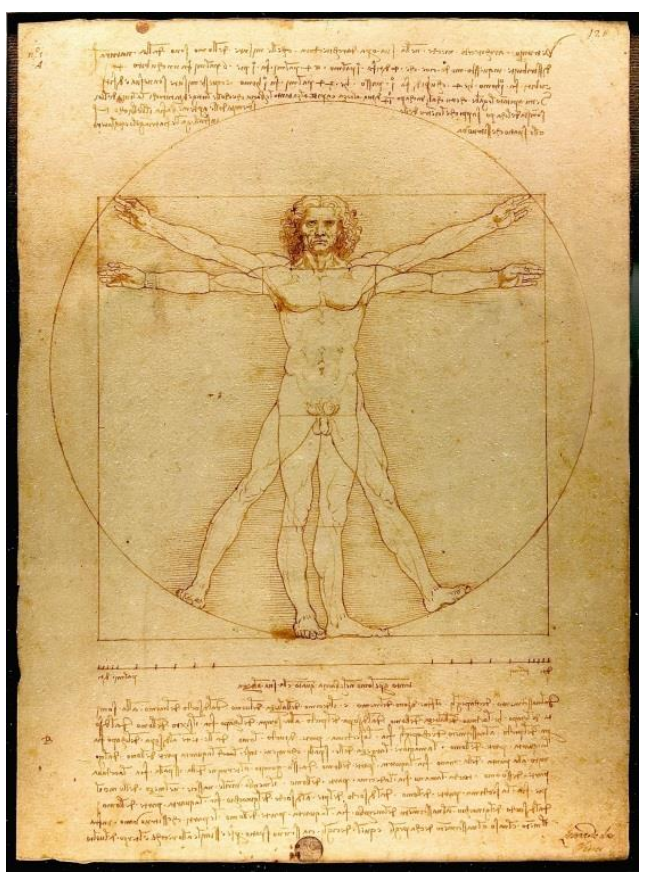

Fonte:

https://pt.wikipedia.org/wiki/Homem_vitr uviano\#/media/File:Da_Vinci_Vitruve_Lu c_Viatour.jpg Imagem de um desenho de estudo de Leonardo da Vinci sobre as proporções do corpo humano. Neste, vemos as ideias de proporção e simetria aplicadas à concepção da beleza humana. 
Para não estender mais, visto que a compreensão das disciplinas História da Arte e Estética carecem de espaço em meu relato para o seu desenvolvimento, atenho-me a apenas observar que: perante uma linha do tempo imaginária da estética, para que a representação do corpo humano, na pintura e na escultura, atingisse o status de belo elas deveriam constituir-se dentro de uma estética de harmonia e razão. Portanto percebo que nas representações da mulher na história da arte como imagem e na sociedade como padrões, não mudaram muito. Pois ainda há uma forte pressão sobre o corpo e imagem da mulher que a força a se enquadrar em um padrão. Seja ele estético ou não ainda seguimos a ideia de modelos, como molde, norma e regra...

\section{Arte e educação: um encontro entre minha poética e docência}

Façamos o exercício de pensar em um quadro, neste quadro há a representação de uma mulher nua. Agora imaginemos e suponhamos estar no momento em que essa obra foi realizada, o que vem a mente? Um pintor e sua modelo? Um estudante e uma modelo? Ou talvez e por último uma artista mulher e sua modelo mulher?

O conceito de artista homem e de sua modelo mulher mantém-se não só na história da arte, como ainda hoje em nossas mentes, até mesmo daqueles que estão inseridos no contexto das artes visuais, se pensarmos, por exemplo, na situação da disciplina Artes na escola onde o professor corre o risco de perpetuar ou não esse legado.

Apesar disso, pesquisadoras e historiadoras ${ }^{\mathrm{ix}}$ vêm rompendo barreiras estabelecidas pelo próprio campo das artes visuais, defendendo e afirmando a mulher na história da arte através de um olhar feminino embargado de conceitos e discursos que colocam em evidência questões associadas à chamada "grande arte", sendo um deles, por exemplo, o mito da genialidade artística:

Uma das categorias da história da arte mais questionadas pelas estudiosas feministas é a figura do artista como gênio e a insistente associação da chamada 'grande arte' com essa imagem heroica, um atributo de características marcadamente masculinas. (LOPONTE, p.248, 2005)

Loponte e Coutinho citam em seu artigo (2015) “Artes visuais e feminismos: implicações pedagógicas.", três estratégias de ação, que essas mulheres investigadoras, desde os anos 1960/1970, vêm utilizando para romper barreiras e tecer uma nova perspectiva de contar e 
estudar a História da Arte. Dentre uma delas, a que me é mais preciosa é a superação dos "clichês da feminilidade", uma vez que está inserida na perspectiva da história da arte ocidental onde:

[...] é recorrente a representação da mulher como 'objeto de desejo', 'objeto de beleza', 'de perdição', 'santificação e pureza' sob o crivo do olhar androcêntrico. Essas são formas de representação imputadas às mulheres por longo tempo - bem como o papel de modelo musa[...] (COUTINHO; LOPONTE, p.183, 2015)

Pensando como as investigadoras, através do olhar feminino, cheio de vontades e desejos de ser e ocupar o espaço de mulher na arte, justifico esse relato sob o caráter de que ele irá contribuir na "[...]minimização do déficit no meio acadêmico e editorial sobre a história das mulheres[...]" (COUTINHO; LOPONTE, 2015). Dando não apenas visibilidade ao estudo da experiência de posar como empoderamento da mulher na sociedade, como nas questões de gênero e sexualidade dentro da arte e educação.

Focada pela ideia inicial de projeto, onde alguns desenhos me bastariam, me iludi com o desenvolver do processo, pois a partir do momento em que comecei a desenhar mulheres que não conhecia, o peso histórico acerca das questões estéticas e dos ideais de beleza, caiu sobre meus ombros, mais especificamente sobre a ponta de meu lápis.

Estariam meus desenhos, desse projeto, representando algum ideal de corpo, uma modelo, uma musa em seu sentido clássico? Ou estariam, ouso aqui dizer, contando e empoderando a história de diferentes mulheres a partir de seus distintos corpos? Desejei trazer para minha poética, a voz da mulher que no passado foi silenciada, apagada, e que a partir dessa vivência pôde se tornar um coro.

Em minha pesquisa poética é explícita a existência da investigação acerca das representações do corpo da mulher. Essa experiência que relatei aqui, vem de encontro aos meus estudos sobre a possibilidade de existir uma "musa" contemporânea - musa no formato mito/tabu, como uma mulher que segue um padrão/ideal de beleza de uma época - com a minha prática docente em sala de aula. É neste momento que me deparo com minha posição de professora de artes, de formadora e educadora, de saberes sobre a arte, no e para o ensino público, e me pergunto: Até onde o que faço como artista atinge ou não o meu aluno? Existe algum diálogo entre as imagens que produzo e as imagens que meu aluno vê em nossa aula de artes? Ou melhor, como Loponte (2002) cita "As imagens dizem muito, nos produzem, nos significam, nos sonham." e continua: 
$\mathrm{Na}$ escola, as aulas de arte, bem ou mal, têm sido o espaço (às vezes o único) de produção e leitura de imagens. Mas de que forma isso acontece? Como professoras de arte (as mulheres são a grande maioria) educam sobre gênero e sexualidade através dessas imagens? E, por outro lado, como elas próprias são educadas através dessas imagens? (LOPONTE, p.285, 2002)

Que imagens de mulheres são vistas pelos meus alunos? Que imagens da arte mostram, e como mostram, a mulher contemporânea para o aluno de hoje? Estaria eu produzindo como artista uma pedagogia visual do feminino para o meu aluno através de meu trabalho?

Desta maneira, Luciana Loponte me faz pensar e revisitar minha graduação. Vindo da Licenciatura, e de um estágio com ela ${ }^{\mathrm{x}}$, acredito não conseguir me desvencilhar da educação quando penso e me posiciono como produtora de imagens, que produzem discursos e pedagogias. Suponho estar em um entre, e afirmo que existe o desejo de continuar a debater e estudar questões que transitam a estética e o poder em minha poética visual, visto que nela está inserida a discussão sobre gênero e sexualidade.

Através de representações artísticas e da produção de sentidos em torno dessas representações exerce-se poder. Poder este que de uma forma não unitária, estável ou fixa vem privilegiando e reforçando um determinado 'olhar masculino'. Poder que, sem dúvida, produz efeitos nos nossos modos de ver e entender questões de gênero e sexualidade. (LOPONTE, p.285, 2002)

Poéticas artísticas, poucas ou raramente, se discutem enquanto produção de imagens que carregam poderes e pedagogias visuais. Luciana elucidando a questão do poder dentro das representações artísticas, encerra minha fundamentação teórica e metodológica neste relato. É junto dela e de outros pesquisadores e pesquisadoras que continuarei visando entender e analisar a "resistência" que venho sendo e produzindo na Linguagem do Desenho através da experiência do posar de outras mulheres. Foucault uma vez disse "onde há poder, há resistência" e seguiu:

(...) os focos de resistência disseminam-se com mais ou menos densidade no tempo e no espaço, às vezes provocando o levante de grupos ou indivíduos de maneira definitiva, inflamando certos pontos do corpo, certos momentos da vida, certos tipos de comportamento. (FOUCAULT, p.92, 1993)

Entendo minha produção como um possível resultado dessa inflamação. E no meu fazer artístico um provável empoderamento de mulheres comuns, mães, filhas, avós, viúvas, casadas, solteiras, em relacionamentos abertos... Mulheres hetero, homo e bissexuais... Tatuadas, peludas, depiladas... Professoras, advogadas, enfermeiras, cabelereiras, estudantes... Tagarelas, exibidas, tímidas, seguras ou não, elas se entregaram à experiência de posar. E sinto que ainda tenho o que dizer sobre elas... 


\section{Referências bibliográficas}

ALZUGARAY, Paula. Feminismo em campo expandido: Artistas tratam da discriminação contra singularidades e da descontrução da noção tradicional de gênero. Select: arte e cultura contemporânea, São Paulo, v. 5, n. 28, p.40-48, fev. 2016. Bimestral.

BEAUVOIR, Simone de. O Segundo Sexo: A experiência vivida. 2. ed. São Paulo: Difusão Européia do Livro, 1967. 2 v.

BONDIA, Jorge Larrosa. Notes on experience and the knowledge of experience. Rev. Bras. Educ., Rio de Janeiro , n. 19, p. 20-28, abr. 2002 . Disponível em <http://www.scielo.br/scielo.php?script=sci_arttext\&pid=S1413$24782002000100003 \& \operatorname{lng}=$ pt\&nrm=iso>. Acesso em 4 abr. 2017.

CHADWICK, Whitney. Mujer, arte y sociedade. Barcelona: Destino, 1992.

COLLING, Ana Maria. Tempos diferentes, discursos iguais: a construção histórica do corpo feminino. Dourados: UFGD, 2014.

CORONA, Marilice. A presença das motivações no(s) escritos de artistas ou fresta para além do que se vê. In: Dinâmicas Epistemológicas em Artes Visuais, $16^{\circ}$, 2007, Florianópolis, $16^{\circ}$ Encontro Nacional da Associação Nacional de Pesquisadores de Artes Plásticas, 2007, p.391403.

COUTINHO, Andréa Senra; LOPONTE, Luciana Gruppelli. Artes visuais e feminismos: implicações pedagógicas. Revista Estudos Feministas, [s.1.], v. 23, n. 1, p.181-190, abr. 2015.

COSTA, Eudes Antônio da. A beleza pela (na) matemática. Estudos, Goiânia, v. 35, n. 2, p.187199, mar/abr. 2008. Bimestral.

FERREIRA, Glória; COTRIM, Cecília. (org.). Escritos de artistas: anos 60/70. Rio de Janeiro: Zahar, 2006.

FOUCAULT, Michel. História da sexualidade I: a vontade de saber. Rio de Janeiro: Edições Graal, 1993.

FOUCAULT, Michel. Vigiar e punir: Nascimento da prisão. 42. ed. Petrópolis: Vozes, 2015.

LOPONTE, Luciana Gruppelli. Gênero, educação e docência nas artes visuais. Educação \& Realidade, Porto Alegre, v. 2, n. 30, p.243-259, 2005. Disponível em: <http://seer.ufrgs.br/index.php/educacaoerealidade/article/view/12469>. Acesso em: 3 mar. 2017.

LOPONTE, Luciana Gruppelli. Sexualidades, artes visuais e poder: pedagogias visuais do feminino. Revista Estudos Feministas, [s.1.], v. 10, n. 2, p.283-300, 2002.

REVEL, Judith. Michel Foucault: conceitos essenciais. São Carlos: Editora Claraluz, 2005. 
SIQUEIRA, Camilla Karla Barbosa. As três ondas do movimento feminista e suas reprercussões no direito brasileiro. In: XXIV CONGRESSO NACIONAL DO CONPEDI UFMG/FUMEC/DOM HELDER CÂMARA, 24., 2015, Belo Horizonte. Congresso. Florianópolis: Conpedi, 2015. p. $328 \quad$ - $354 . \quad$ Disponível em: <http://www.conpedi.org.br/publicacoes/66fs1345/w8299187/ARu8H4M8AmpZnw1Z.pdf>. Acesso em: 19 jun. 2017.

STRECKER, Márion. Lisette Lagnado: a fala é o falo. Select: arte e cultura contemporânea, São Paulo, v. 5, n. 28, p.36-39, fev. 2016. Bimestral.

\footnotetext{
${ }^{i}$ Licenciada em Artes Visuais pela Universidade Federal do Rio Grande do Sul (2014). É professora de Artes na Rede Estadual de Educação de Santa Catarina. Tem experiência na área de Artes, Educação, com ênfase em Artes Plásticas. Participa como pesquisadora colaboradora do Grupo de Pesquisa em Arte GPA/CNPq e da Formação Continuada do Arte na Escola Polo UNESC ambos na Universidade do Extremo Sul Catarinense. Desenvolve produção artística desde 2009 acerca dos temas: mulher, estética e padrões estéticos do contemporâneo, desenho e suas formas de pensar.

${ }^{\text {ii }}$ Convite enviado a mim por e-mail pela Gabriela Maruno, Produtora Cultural - Chefia da Divisão de Cultura, Próreitora de Extensão e Cultura da Universidade Federal do ABC, no dia 13 de Setembro de 2016.

iii Galeria de arte contemporânea situada na cidade de São Bernardo do Campo.

iv Marilice Corona defenderá os Escritos de Artista afirmando em seu artigo (2007) que "A grande relevância da reunião destes escritos é nos aproximar do universo, das intenções e das análises que os artistas fazem de sua própria produção. Aqui não é o historiador, o crítico, ou seja, o teórico quem tem a palavra, mas o produtor.", dessa forma, o que relato e escrevo sobre minha própria produção artística é de relevante para análises e estudos.
}

"Assim como Larrosa em suas "Notas sobre a experiência e o saber de experiência" acredito que esse projeto se encaixa perfeitamente quando ele diz que "A experiência é o que nos passa, o que nos acontece, o que nos toca.".

${ }^{\text {vi }}$ Considero uma pose inusitada aquela que foge dos padrões de retrato. Posições estáticas, com os braços junto ao corpo, como em pinturas barrocas que retratavam famílias, reis e rainhas, assim como fotografias de retrato do final do século XIX e início do século XX.

vii Ou pôster lambe-lambe, é um tipo de pôster com propósitos diferentes que podem transmitir desde ideias e pensamentos, divulgação de eventos e arte, a protestos, elaborados através de imagens e textos. Podem ser feitos de técnicas e tamanhos variados. São considerados uma vertente da arte urbana onde realiza-se intervenções nos espaços públicos. Normalmente quando feitos em série são cópias Xerox ou de copiadoras a laser. A cola é feita a base de água, com polvilho ou farinha, caráter acessível dessa expressão artística. São colados em espaço público. (texto informado pelo autor)

viii Sufragistas podem ser mulheres e homens que lutaram pelo direito da mulher ao voto. Também conhecido como movimento pelo sufrágio feminino. (texto informado pelo autor)

ix "Pesquisadoras e historiadoras como Griselda Pollock(1988), Patrícia Mayayo (2003), Linda Nochlin (1989, 1989a), Bea Porqueres (1994) e Whitney Chadwick (1992) [...] fazem coro diante da desconstrução de um mito, [...] do que seja arte ou artista." (LOPONTE, p.248, 2005)

${ }^{x}$ Fui aluna da Prof ${ }^{a}$. Dr ${ }^{\mathrm{a}}$. Luciana Gruppelli Loponte, nas disciplinas de Estágio I e II no ano de 2014 em que finalizava o curso de Licenciatura em Artes Visuais pela Universidade Feral do Rio Grande do Sul. 